\title{
Erratum to: The fallopian canal: a comprehensive review and proposal of a new classification
}

\author{
M. M. Mortazavi • B. Latif $\cdot$ K. Verma $\cdot$ N. Adeeb $\cdot$ \\ A. Deep • C. J. Griessenauer • R. S. Tubbs • T. Fukushima
}

Published online: 28 January 2014

(C) Springer-Verlag Berlin Heidelberg 2014

\section{Erratum to: Childs Nerv Syst \\ DOI 10.1007/s00381-013-2332-0}

The original version of this article unfortunately contained some error.

1. On figure 1, "Internal acoutic meatus" should be "Internal acoustic meatus".

2. Corrected figure can be found below.

3. The following are part of the reference section. Citations should be after the 3rd sentence of the "Conclusions and proposal of a new anatomical classification" section.

The online version of the original article can be found at http://dx.doi.org/ 10.1007/s00381-013-2332-0.

M. M. Mortazavi $\cdot$ B. Latif $\cdot$ K. Verma $\cdot$ N. Adeeb $\cdot$ A. Deep ·

C. J. Griessenauer

Pediatric Neurosurgery, Children's of Alabama, Birmingham,

AL, USA

R. S. Tubbs $(\bowtie)$

Department of Anatomical Sciences, St. George's University,

True Blue, Grenada

e-mail: shane.tubbs@childrensal.org

T. Fukushima

Division of Neurological Surgery, Duke University,

Durham, NC, USA

\section{R. S. Tubbs}

Centre of Anatomy and Human Identification, Dundee University,

Dundee, UK

53. Kveton JF (1992) The facial nerve in revision mastoid surgery: Avoiding complications. Operative Techniques in Otolaryngology-Head and Neck Surgery 3: 69-72

54. Maru N, Cheita AC, Mogoanta CA, Prejoianu B (2010) Intratemporal course of the facial nerve: morphological, topographic and morphometric features. Romanian journal of morphology and embryology $=$ Revue roumaine de morphologie et embryologie 51: 243-248

55. Weiglein AH (1996) Postnatal development of the facial canal. An investigation based on cadaver dissections and computed tomography. Surgical and radiologic anatomy: SRA 18: $115-123$

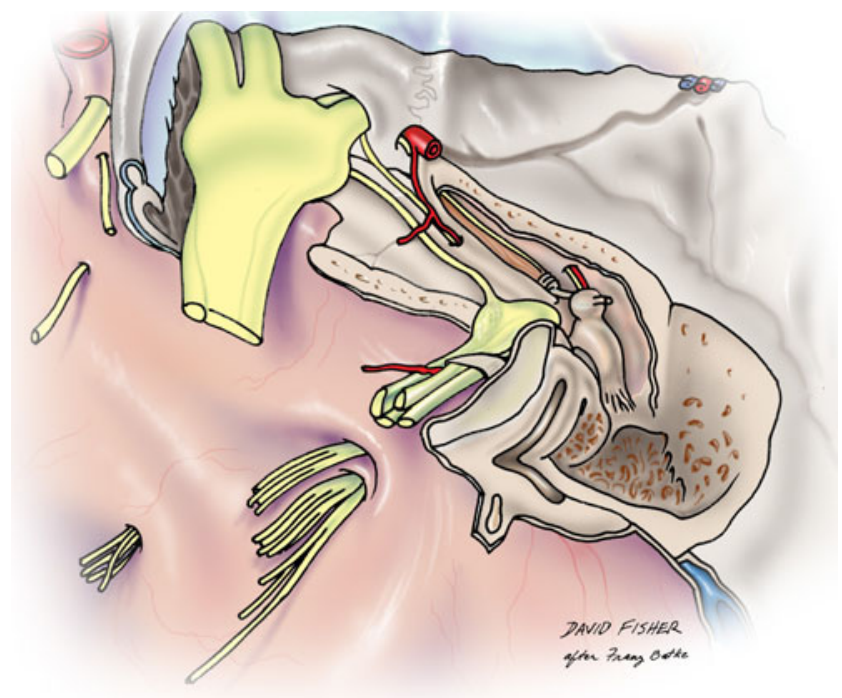

